\title{
Physical and Psychological Factors and the Reproductive Outcomes of Women Undergoing In-Vitro Fertilization Treatment
}

\author{
Heba M. Mohamed ${ }^{1}$,Walaa H. Ibrahim ${ }^{2}$,Amal A. Abdelhafez ${ }^{3}$,Ola A. Abd El- Fatah ${ }^{4}$ \& Tarek A. Abdel-salam \\ ${ }^{1 \& 2}$ Lecturer of Obstetrics \& Gynecological Nursing, Faculty of Nursing, Assiut University, Egypt. \\ ${ }^{3}$ Lecturer of Obstetrics \& Gynecological Nursing, Faculty of Nursing, Minia University, Egypt. \\ ${ }^{4}$ Lecturer of Psychiatric Nursing, Faculty of Nursing, Assiut University, Egypt. \\ ${ }^{5}$ Assisstant professor of Obstetrics \& Gynecological Medicine, Faculty of Medicine, Assiut University, Egypt.
}

\begin{abstract}
Background: In-Vitro Fertilization (IVF) can be affected by both physical and psychological stressors that affect endocrine axis and the reproductive system through immunosuppression. In any society, attention to physical and mental health status is considered as the guarantee for community health in the coming years. One of the issues that trouble the mental health of some people is infertility. The aim of the study is to determine the physical and psychological factors affecting outcomes of women undergoing IVF. Setting, this study conducted at IVF unit, woman's health hospital, Assiut University. Methods: Sample size included 100 women under IVF treatment, a predictive correlational research design was used, Tools: Three tools, included interview questionnaire, Hamilton Anxiety Rating Scale and Hamilton depression Rating Scale. Results: There are statistical significant differences between IVF outcomes and women's age, physical health problems and psychological stress. Conclusion: physical factors such as women's age, weight, female factors and psychological stressors such as anxiety and depression play a vital role in success of IVF outcomes. Recommendations: Educating women at the beginning, in infertility centers on the impact of physical and psychological factors that can affect management is effective part of nurses and physicians active role and larger studies are still required.
\end{abstract}

Keywords: Physical, Psychological Factors \&Reproductive Outcomes, In-Vitro Fertilization Treatment.

\section{Introduction}

Assisted Reproductive Technologies (ART) nowadays is a very important technique and IVF is the greatest effective procedure that helps many couples to conceive. It includes putting an ovum and sperm together in a plastic dish to be fertilized. ICSI is a special form of IVF, in which a mature ovum is directly injected by a particular sperm done under a microscope by qualified technicians, if the egg is fertilized, the embryo is transfer into the uterus. But its effectiveness depends on some important factors which may affect its successfulness as age, previous pregnancy, uterine abnormalities, period of infertility, overweight and fertility clinic selection (Merck, 2015 \& SCRC, 2016).

Steven et al., (2012) findings suggested that both couple undergoing an IVF-management loaded with many physical, mental and psychological burdens. So couples coming on a treatment program of IVF are in general should be psychologically well-adjusted because couple during the way of management and especially time staying for the pregnancy outcome and failed IVF are the most stressful time.

Many studies revealed that physical and psychological factors affect gestational women which increase several complications as spontaneous expulsion of fetus, preeclampsia, preterm labour and decreased birth weight, so the assessment of stressor factors during pregnancy as a general and especially
IVF/ICSI is important because its side effects for mother and their child and necessary to eradicate stress for successful infertility treatment (Ibanez, et al., 2012 \& Coelho, et al., 2011).

When the couples begins treatment they have to tolerate and bear variety of stages as ovarian stimulation, regular monitoring, retrieval of the oocyte, transfer the embryo and progesterone hormone supplementation (Williams \& Wilkins, 2014). Furthermore the daily couple's routines greatly disturbed by treatment appointments, investigations, and daily injections, therefore couples complain of stressful experience especially fear of that it will fail (Li-, et al., 2015).

Anxiety and depressive symptoms experience has been produce to be related to pregnancy failure. So the stress and reproduction are correlated. Preconception stress could elevate the infertility risk and psychological stress as depression, worry and anxiety was negatively related to a positive outcome of pregnancy after IVF (Feijing Zhou \& Yuezhi Dong, 2016). At the beginning of IVF process, change couple's feeling to anxiety and may reach to depression symptoms, while after failed IVF procedure, feelings of sadness, depression and anger prevail. Also worry continues after positive IVFtreatment outcome and parents remain more stressful during pregnancy than normal fertile' parents. Mothers conceived by IVF demonstrate a high 
quality of parent-child relationship than mothers with a normally reproduced child (Steven, et al., 2012).

Recent studies demonstrate that psychologically distress may deteriorate fertility and that depressive symptoms may minimize the effectiveness of infertility management. Several studies conducted within the past three years support the theory that psychologically distress can have a significant adverse effect on successive rates IVF/ ICSI. Researches have terminated that the successful rates of infertility management can be adversely influenced by psychological stress (Domar et al., 2013).

Infertility nurse have a vital role during IVF journey from diagnosis to treatment and pregnancy (Eric Levens, 2011). These actions and interventions that nurse perform include communications with infertile women, interview with them, treatment follow up, teach them how to take their medications, give instructions about treatment options. She also give instruction about investigation needed, assist in physical examination and embryo transfer (Brittany Hamstra, 2017). All these actions act as a skillful help to reduce women anxiety that help later to increase chance of pregnancy (Eric Levens, 2011).

\section{Significant of the study}

Couples undergoing IVF procedure may run a range of strong or intense emotions. Moods can fluctuating from hope to fear, from joy to disappointment. Couples 'experience and how cope will be based on a wide number of individual psychological factors including Couples' personality, support network, the relationship of couple to each others and others various physical factors affect IVF outcomes as maternal age, basal FSH, duration and indication of subfertility, number of ovum retrieved, method of fertilization, transferred embryo's number, and its quality (Merck, 2015, Adam et al., 2014 \& Van, 2010). So recently the part that has a great interest is effect of psychological stress as soon as physical potentially in determining the outcomes after IVF and its important issue for nursing profession to apply nursing counseling role and psychotherapy for the further researches.

\section{Aim of the study}

-This study aimed to determine the physical and psychological factors among women undergoing IVF correlates with the reproductive outcomes.

\section{Research questions}

- What is the physical factors affecting outcomes of women undergoing IVF?

- Are the psychological factors as anxiety and depression affecting outcomes of women undergoing IVF or not?
Anxiety is a term used to describe a normal feeling people experience when faced with threat, danger, or when stressed. When people become anxious, they typically feel upset, uncomfortable, and tense (Holden J, 2015).

Depression is a common mental disorder that presents with depressed mood, loss of interest or pleasure, decreased energy, feelings of guilt or low self-worth, disturbed sleep or appetite, and poor concentration (Timothy J, 2017).

\section{Materials \& method}

\section{Research design:}

A predictive correlational research design was used for the current study.

\section{Patient \& study setting:}

The study was conducted at IVF unit, woman's Health Hospital, Assiut University, Egypt. Regarding sample size, it was calculated by Epi-Info 7.2.0.1 using the sample size equation for estimation of single proportion. With precision levels $5 \%$ where confidence level is $95 \%$ and $\mathrm{p}<0.05$. The optional sample size was 93. The actual sample increased to 100 women undergoing IVF treatment to compensate any dropout which chosen by convenient sample included all infertile women undergoing IVF procedures who agree to participate in the study with exclusion to women who suffering from or with history of psychosomatic and psychiatric diseases or refused to participate in the study.

\section{Tools of the study}

\section{Tool I: Structured interview questionnaire}

Data was collected by using interview questionnaire that was designed by researcher included two part, part one involved personal data, medical history, previous IVF data and its outcomes and part two involved Charleston Psychiatric Outpatient Satisfaction Scale as an essential part of psychological factors help women to continue treatment and even after failed IVF, try again. It was adapted to suit the IVF unit at woman's Health Hospital, Assiut University. It consist of nine items, each item are scored using the five point scale as excellent, very good, good, fair and poor which discuss the satisfaction of women about relation to physician, nurses, medical assistant, questions answered and options clearly explained, helpful \& friendly...etc.

Tool II: Hamilton Anxiety Rating Scale (HAM-A) which was developed by Hamilton, et al., (1988). It was one of the first rating scales developed to measure the severity of anxiety symptoms, and is still widely used today in both clinical and research settings. The scale consists of 14 items, each defined by a series of symptoms, and measures both psychic anxiety (mental agitation and psychological distress) 
and somatic anxiety (physical complaints related to anxiety).

\section{Scoring system}

Each of the 14 items contains a number of symptoms, Each item is scored on a scale of 0 (not present) to 4 (severe), with a total likert score range of 0-56, where <17 indicates mild severity, 18-24 mild to moderate severity and 25-30 moderate to severe while a score of 31-56 indicates a very sever anxiety.

Tool III: Hamilton Rating Scale for Depression (HRSD) which was developed by Hamilton M, et al, (1979) and was translated into Arabic by Elmistkawy, (2004) and back translated into English to check its validity and was updated by Steve (2010). The questionnaire is designed for adults and is used to measure the severity of their depression by probing mood, feelings of guilt, suicide ideation, insomnia, agitation or

retardation, anxiety, weight loss, and somatic symptoms.

\section{Scoring system}

The scale is widely available and has two common versions with either 17 or 21 items and is scored between 0 and 4 points. The first 17 items measure the severity of depressive symptoms and as examples the interviewer rates the level of agitation clinically noted during the interview or how the mood is impacting on an individual's work. The extra four items on the extended 21-point scale measure factors that might be related to depression, but are not thought to be measures of severity, such as paranoia or obsessional and compulsive symptoms. Scoring is based on the 17-item scale and scores of $0-12$ are considered as being normal, 13-16 suggest mild depression, 17-19 moderate depression and scores over 20 are indicative of severe depression.

Validity and reliability of the study tools

The validity of study tools was measured and reviewed from committee of experts in the field of Obstetrics and Gynecological nursing and medical staff and also psychiatric nursing staff and modification performed included remove unnecessary parts as medications used and modify the satisfaction scale. The reliability of the study tools was assessed in a pilot study by measuring their internal Consistency using Cronbach's alpha method. This turned to be $(\alpha=0.89)$ to study tool.

\section{Operational design:}

This included the pilot study and data collection phase.

\section{Pilot study}

A pilot study was conducted on a sample of $10 \%$ of women attending to IVF unit, woman's Health Hospital, Assiut University to test the applicability of the tools and test the clarity of the designated questionnaire as well as to estimate the time needed to answer it. It also helped to test the feasibility and suitability of the study settings. Data obtained from the pilot were excluded from the number of study sample because addition of essential part inspired when I was talking to the women, they mentioned their psychological dissatisfaction about other private centers of IVF, so they left it and did not complete the procedure of IVF or try again.

\section{Administration design}

To carry out the study; the necessary approval was obtained from the Dean of the faculty of nursing in Assiut University. The researcher explained the aim of the study and requesting permission to use the premise for data collection.

\section{Ethical consideration}

The study proposal took agreement from the ethical committee of the faculty of nursing, Assiut University. An official permission to carry out the study was obtained from the responsible authorities from woman's health hospital after inform them about the objectives of the study and to gain the needed support and cooperation.

Informed consent was obtained from the study participants after explaining the purpose and nature of the study. Also, assure them that their participation would not be used against them in any way and they have the right to refuse or to decide to terminate their participation at any time.

\section{Data collection phase}

Data were collected through interviewed the women at IVF unit after explanation the nature of the study and obtained their consent to be included in the study. The researcher informed the participant that their participation is voluntary. Confidentiality and anonymity of subjects were assured by the researcher. Tool I (Structured interview questionnaire) collected by obstetrics and gynecological nursing researcher at the same time tool II and III (Hamilton Anxiety and Depression Rating Scale) collected and analyzed by psychiatric nursing staff involved in research. Data were collected in two day by week for the presence of both obstetrics \& gynecological and psychological nursing researchers.

The data collection took about 30 minutes for each participant and started from January 2017 to January 2018 (the data collection stopped in Ramadan month according to the protocol of center for the difficult to obtain fresh semen analysis from husband).

Follow up

Follow up of cases was done after duration of two weeks from the implementation or transfer of fertilized egg by the researchers' medical and nursing staff to assess IVF procedures outcomes as positive or negative pregnancy and until six months for positive cases to ensure that pregnancy is continuing or end with abortion but scale of anxiety and 
depression not repeated because It is difficult and long to ask in the phone and all of cases having uncontrolled stress until the expected day of pregnancy test and waiting for outcome followed by a feeling of happiness for the positive result and sadness for negative result and in positive cases continuing with feeling of fear from abortion and movement restriction in the first six months according to women discussion.

\section{Statistical design}

Data entry and analysis were done using SPSS version 20 Program statistical software package for social sciences. Data were presented using descriptive statistics in the form of frequencies and percentages. Also, Mean and standard deviations were calculated. Correlation between variables (ChiSquare) and (t-test) were used statistical significance was considered at $\mathrm{P}$-value $\leq 0.05$.

\section{Result}

Table (1): Distribution of studied women according to their personal data.

\begin{tabular}{|c|c|c|}
\hline Personal data & No. (100) & $\%$ \\
\hline \multicolumn{3}{|l|}{ Age: (years) } \\
\hline Less than 25 years & 10 & 10.0 \\
\hline $25-30$ year & 37 & 37.0 \\
\hline More than 30 years & 53 & 53.0 \\
\hline Mean \pm SD (Range) & \multicolumn{2}{|c|}{$30.1 \pm 4.6$} \\
\hline \multicolumn{3}{|l|}{ Occupation } \\
\hline House wife & 84 & 84.0 \\
\hline Employer & 16 & 16.0 \\
\hline \multicolumn{3}{|l|}{ Residence } \\
\hline Urban & 37 & 37.0 \\
\hline Rural & 63 & 63.0 \\
\hline \multicolumn{3}{|l|}{ Type of family } \\
\hline Nuclear & 46 & 46.0 \\
\hline Extended family & 54 & 54.0 \\
\hline \multicolumn{3}{|l|}{ Education } \\
\hline Illiterate & 30 & 30.0 \\
\hline Read and write & 18 & 18.0 \\
\hline Basic education & 37 & 37.0 \\
\hline Secondary & 15 & 15.0 \\
\hline
\end{tabular}

Table (2): Distribution of studied women according to their physical status.

\begin{tabular}{|l|c|c|}
\hline \multicolumn{1}{|c|}{ Maternal physical status } & No. (100) & \% \\
\hline Maternal medical problems & \multicolumn{2}{c|}{} \\
\hline Non & 53 & 53.0 \\
\hline Diabetes mellitus & 3 & 2.0 \\
\hline Hypertension & 2 & 1.0 \\
\hline Diabetes\& Hypertension & 1 & 1.0 \\
\hline Hyperthyroidism & 1 & 2.0 \\
\hline Respiratory disorder & 2 & $\mathbf{1 3 . 0}$ \\
\hline Poor ovarian reserve & 13 & 5.0 \\
\hline Infections & 5 & 6.0 \\
\hline PCO & 6 & 10.0 \\
\hline$*$ Other & 10 & 4.0 \\
\hline mix problems & 4 & $\mathbf{1 0 0}$ \\
\hline Total & $\mathbf{1 0 0}$ & 7.0 \\
\hline Body weight & & \multicolumn{2}{|c|}{} \\
\hline Underweight & 7 & 56.0 \\
\hline Normal weight & 56 & $\mathbf{3 7 . 0}$ \\
\hline Obese & 37 & $\mathbf{1 0 0}$ \\
\hline Total & $\mathbf{1 0 0}$ & \\
\hline
\end{tabular}

* Others involved tubal and pelvic adhesion, PID and hydrosalpinx, fibroid and endometriosis. 
Table (3): Distribution of the studied women about their fertility history:

\begin{tabular}{|l|c|c|}
\hline \multicolumn{1}{|c|}{ Fertility history } & \multicolumn{2}{c|}{ No. (100) } \\
\hline Duration of infertility & 26 & 26.0 \\
\hline Less than 5 years & 47 & $\mathbf{4 7 . 0}$ \\
\hline 5-10 years & 27 & 27.0 \\
\hline More than10 years & \multicolumn{2}{|c|}{} \\
\hline Type of infertility & 93 & $\mathbf{9 3 . 0}$ \\
\hline Primary & 7 & 7.0 \\
\hline Secondary & \multicolumn{2}{|c|}{} \\
\hline cause(s) of infertility & 37 & $\mathbf{3 7 . 0}$ \\
\hline Male & 33 & 33.0 \\
\hline Female & 17 & 17.0 \\
\hline Mixed & 13 & 13.0 \\
\hline Unexplained & \multicolumn{2}{|c|}{} \\
\hline History of IVF & 25 & $\mathbf{2 5 . 0}$ \\
\hline Yes & 75 & 75.0 \\
\hline No & \multicolumn{2}{|c|}{} \\
\hline Outcomes of previous IVF if yes & 7 & $\mathbf{2 8 . 0}$ \\
\hline Positive for pregnancy & 18 & $\mathbf{1 0 0}$ \\
\hline Negative for pregnancy & $\mathbf{2 5}$ & \\
\hline Total & \multicolumn{2}{|c|}{} \\
\hline
\end{tabular}

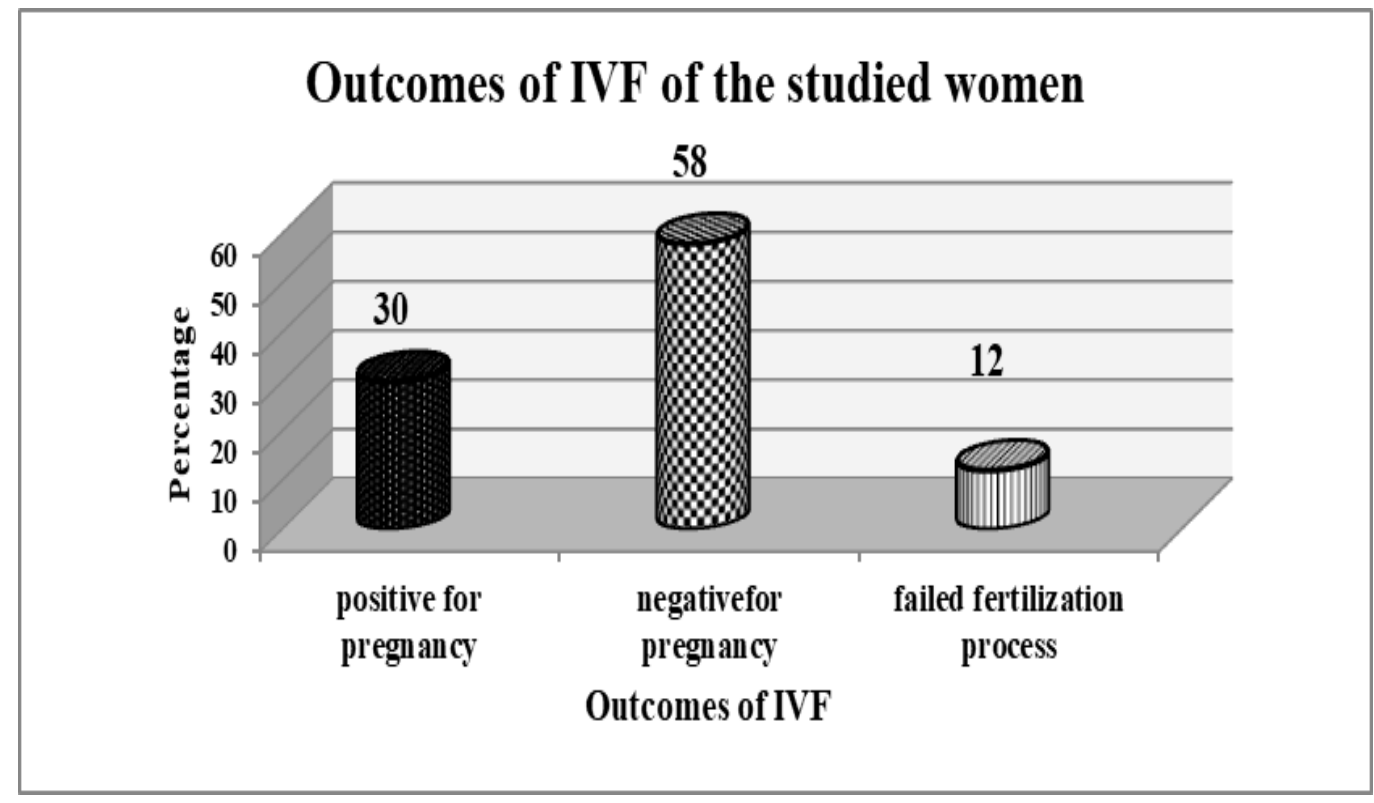

Figure (1): Distribution of the studied women according to their IVF outcomes. 


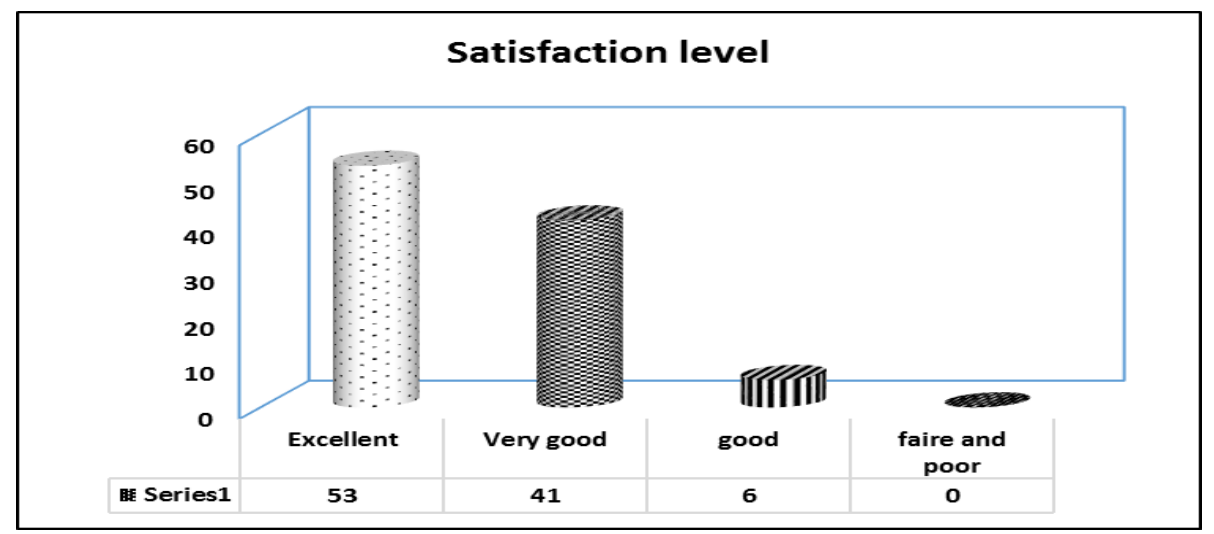

Figure (2): Satisfaction level of the studied women

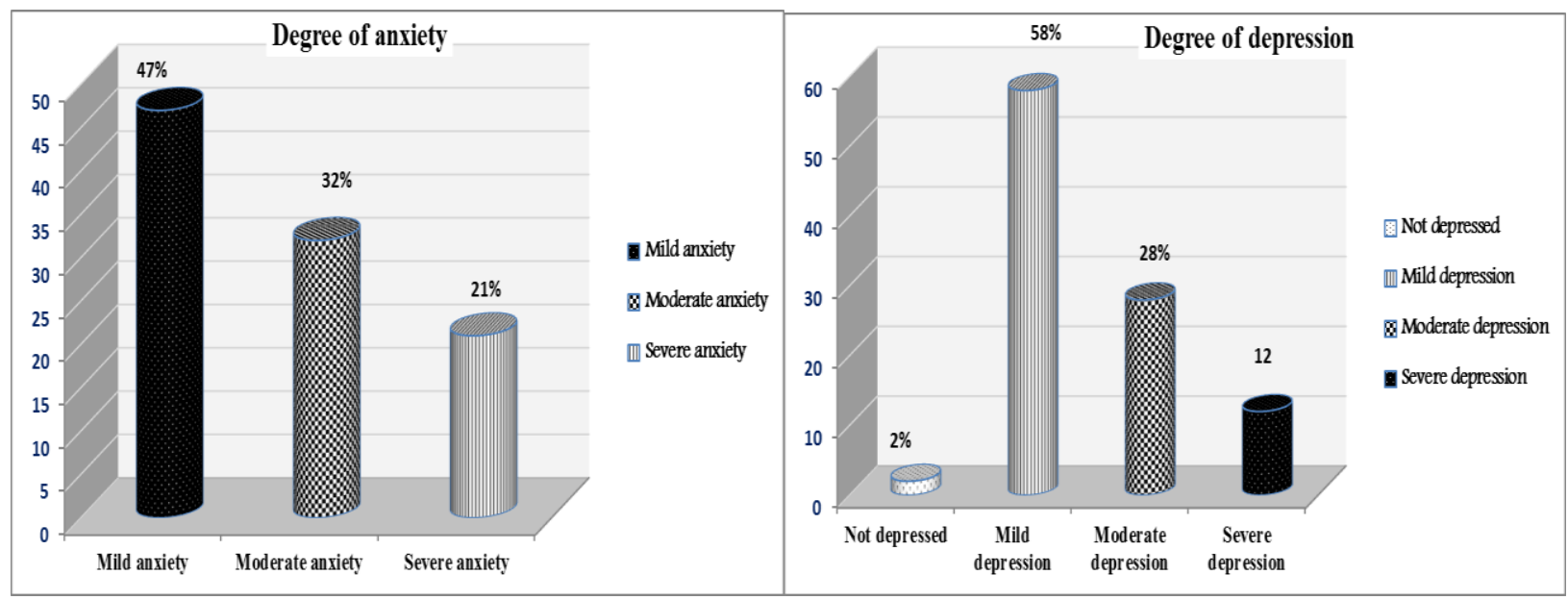

Figure (3): Psychological stress of the studied women

Table (4): Correlation between outcomes of IVF studied women and their personal data.

\begin{tabular}{|c|c|c|c|c|c|c|}
\hline \multirow{2}{*}{\multicolumn{2}{|c|}{ personal characteristics }} & \multicolumn{3}{|c|}{ Outcomes of IVF } & \multirow{3}{*}{$\begin{array}{c}\text { Total } \\
10 \\
\end{array}$} & \multirow{3}{*}{$\begin{array}{l}\text { p-value } \\
.001 *\end{array}$} \\
\hline & & \multirow{2}{*}{$\begin{array}{c}\begin{array}{c}\text { Positive } \\
\text { Pregnancy }\end{array} \\
8\end{array}$} & \multirow{2}{*}{$\begin{array}{c}\begin{array}{c}\text { Negative } \\
\text { Pregnancy }\end{array} \\
0\end{array}$} & \multirow{2}{*}{$\begin{array}{c}\begin{array}{c}\text { Failed } \\
\text { fertilization } \\
\text { process }\end{array} \\
2\end{array}$} & & \\
\hline Age & Less than 25 year & & & & & \\
\hline & $25-30$ year & 14 & 20 & 3 & 37 & \\
\hline & More than 30 years & 8 & 38 & 7 & 53 & \\
\hline Total & & 30 & 58 & 12 & 100 & \\
\hline Occupation & House wife & 23 & 51 & 10 & 84 & .392 \\
\hline & Employer & 7 & 7 & 2 & 16 & \\
\hline Total & & 30 & 58 & 12 & 100 & \\
\hline Education & Illiterate & 9 & 14 & 7 & 30 & .064 \\
\hline & Read and writes & 3 & 14 & 1 & 18 & \\
\hline & Basic education & 10 & 23 & 4 & 37 & \\
\hline & Secondary & 8 & 7 & 0 & 15 & \\
\hline Total & & 30 & 58 & 12 & 100 & \\
\hline
\end{tabular}

*Negative pregnancy mean failed of pregnancy occur after embryo transfer into the uterus while failed fertilization process mean bad quality of egg during conception time so not transfer to the woman's uterus. 
Table (5): Correlation between outcomes of IVF studied women and their physical condition.

\begin{tabular}{|c|c|c|c|c|c|c|}
\hline \multirow{2}{*}{\multicolumn{2}{|c|}{ Maternal physical condition }} & \multicolumn{3}{|c|}{ Outcomes of IVF } & \multirow{3}{*}{$\begin{array}{c}\text { Total } \\
53 \\
\end{array}$} & \multirow{3}{*}{$\begin{array}{l}\text { p-value } \\
\text { 0.001* }\end{array}$} \\
\hline & & \multirow{2}{*}{$\begin{array}{c}\begin{array}{c}\text { Positive } \\
\text { Pregnancy }\end{array} \\
21\end{array}$} & \multirow{2}{*}{$\begin{array}{c}\begin{array}{c}\text { Negative } \\
\text { Pregnancy }\end{array} \\
29\end{array}$} & \multirow{2}{*}{$\begin{array}{c}\begin{array}{c}\text { Failed } \\
\text { fertilization } \\
\text { process }\end{array} \\
3\end{array}$} & & \\
\hline Maternal & None & & & & & \\
\hline history of & Diabetes mellitus & 1 & 2 & 0 & 3 & \\
\hline physical & Hypertension & 0 & 2 & 0 & 2 & \\
\hline disease & $\begin{array}{l}\text { Diabetes\& } \\
\text { Hypertension }\end{array}$ & 0 & 0 & 1 & 1 & \\
\hline & Hyperthyroidism & 0 & 1 & 0 & 1 & \\
\hline & Respiratory disorder & 1 & 0 & 1 & 2 & \\
\hline & Poor ovarian reserve & 1 & 5 & 7 & 13 & \\
\hline & Infections & 1 & 4 & 0 & 5 & \\
\hline & $\mathrm{PCO}$ & 1 & 5 & 0 & 6 & \\
\hline & Other & 2 & 8 & 0 & 10 & \\
\hline & mix problems & 2 & 2 & 0 & 4 & \\
\hline Total & & 30 & 58 & 12 & 100 & \\
\hline Body & Underweight & 2 & 4 & 1 & 7 & .395 \\
\hline weight & Normal weight & 21 & 30 & 5 & 56 & \\
\hline & Obese woman & 7 & 24 & 6 & 37 & \\
\hline Total & & 30 & 58 & 12 & 100 & \\
\hline
\end{tabular}

Table (6): Correlation between outcomes of IVF studied women and their history of infertility.

\begin{tabular}{|c|c|c|c|c|c|c|}
\hline \multirow{2}{*}{\multicolumn{2}{|c|}{ Infertility history }} & \multicolumn{3}{|c|}{ Outcomes of IVF } & \multirow[b]{2}{*}{ Total } & \multirow{2}{*}{$\begin{array}{c}\text { p- } \\
\text { value }\end{array}$} \\
\hline & & Positive & Negative & $\begin{array}{c}\text { Failed } \\
\text { fertilization }\end{array}$ & & \\
\hline \multirow{3}{*}{$\begin{array}{l}\text { Duration of } \\
\text { infertility }\end{array}$} & Less than 5 years & 6 & 16 & 4 & 26 & \multirow{4}{*}{0.317} \\
\hline & $5-10$ years & 17 & 23 & 7 & 47 & \\
\hline & More than 10 years & 7 & 19 & 1 & 27 & \\
\hline Total & & 30 & 58 & 12 & 100 & \\
\hline \multirow{2}{*}{$\begin{array}{c}\text { Type of } \\
\text { infertility }\end{array}$} & Primary & 27 & 55 & 11 & 93 & \multirow[b]{3}{*}{0.689} \\
\hline & Secondary & 3 & 3 & 1 & 7 & \\
\hline Total & & 30 & 58 & 12 & 100 & \\
\hline \multirow{4}{*}{$\begin{array}{l}\text { Cause(s) of } \\
\text { infertility }\end{array}$} & Male & 12 & 20 & 5 & 37 & \multirow{5}{*}{0.502} \\
\hline & Female & 11 & 18 & 4 & 33 & \\
\hline & Mixed & 2 & 14 & 1 & 17 & \\
\hline & Unexplained & 5 & 6 & 2 & 13 & \\
\hline Total & & 30 & 58 & 12 & 100 & \\
\hline
\end{tabular}

Table (7): Correlation between outcomes of IVF studied women and their psychological factors.

\begin{tabular}{|l|l|c|c|c|c|c|}
\hline \multicolumn{2}{|c|}{} & \multicolumn{3}{c|}{ Outcomes of IVF } & \multirow{2}{*}{ Total } & \multirow{2}{*}{ p-value } \\
\cline { 2 - 6 } \multicolumn{2}{|c|}{ Psychological stress } & $\begin{array}{c}\text { Positive } \\
\text { Pregnancy }\end{array}$ & $\begin{array}{c}\text { Negative } \\
\text { Pregnancy }\end{array}$ & $\begin{array}{c}\text { Failed } \\
\text { fertilization } \\
\text { process }\end{array}$ & & \\
\hline \multirow{2}{*}{ Anxiety } & Mild anxiety & 26 & 18 & 3 & 47 & \multirow{2}{*}{$0.00 *$} \\
\cline { 2 - 6 } & Moderate anxiety & 4 & 24 & 4 & 32 \\
\cline { 2 - 6 } & Severe anxiety & 0 & 16 & 5 & 21 & \\
\hline Total & & $\mathbf{3 0}$ & $\mathbf{5 8}$ & $\mathbf{1 2}$ & $\mathbf{1 0 0}$ & \\
\hline
\end{tabular}




\begin{tabular}{|c|c|c|c|c|c|c|}
\hline \multirow{2}{*}{\multicolumn{2}{|c|}{ Psychological stress }} & \multicolumn{3}{|c|}{ Outcomes of IVF } & \multirow{3}{*}{$\begin{array}{c}\text { Total } \\
2 \\
\end{array}$} & \multirow{3}{*}{ p-value } \\
\hline & & \multirow{2}{*}{$\begin{array}{c}\begin{array}{c}\text { Positive } \\
\text { Pregnancy }\end{array} \\
1\end{array}$} & \multirow{2}{*}{$\begin{array}{c}\begin{array}{c}\text { Negative } \\
\text { Pregnancy }\end{array} \\
1\end{array}$} & \multirow{2}{*}{ 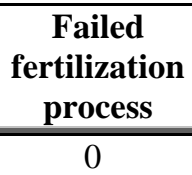 } & & \\
\hline \multirow[t]{4}{*}{ Depression } & Not depressed & & & & & \\
\hline & Mild depression & 29 & 24 & 5 & 58 & \multirow{4}{*}{$0.000 *$} \\
\hline & $\begin{array}{l}\text { Moderate } \\
\text { depression }\end{array}$ & 0 & 22 & 6 & 28 & \\
\hline & Severe depression & 0 & 11 & 1 & 12 & \\
\hline Total & & 30 & 58 & 12 & 100 & \\
\hline
\end{tabular}

Table (1): Illustrate personal data of participating women, their age ranged from 18 to 42 years. Most of them aged more than 30 years $(53 \%)$ with mean age of $30.1 \pm 4.6$ years. The majority of women $(84 \%)$ were housewives and were rural resident live in husband's family house $(63.0 \% \quad \& \quad 54 \%$, respectively). women having secondary education and illiterate constituted $(37.0 \% \& 30 \%$, respectively) of studied women.

Table (2): Demonstrate the physical status of infertile women, about half of women $(53 \%)$ free from any health problems with a benefit on the IVF outcomes but another women complain of health problems, most of these diseases are confined to poor ovarian reserve $(13 \%)$, PCO $(6 \%)$ and $(4 \%)$ with mixed problems. Concerning to body weight more half of women $(56 \%)$ with normal weight followed by $(37 \%)$ Obese women.

Table (3): Reveals that around half of women (47\%) had a duration of infertility between 5 to 10 years and about one third $(27 \%)$ of studied women were infertile for more than 10 years. Most of them (93\%) have primary infertility. Regarding causes of infertility the results found that more than one third of infertility (37\%) due to male factors and one third (33\%) with female factors while $30 \%$ with mixed and unexplained causes and demonstrates that one quarter of studied women (25\%) have a history of IVF, $28 \%$ of women performed IVF have a positive pregnancy test.

Figure (1): Display the outcomes of women undergoing IVF, It was found that the higher percentage of women about two third (70\%) with negative pregnancy test and failed fertilization process, and only one third of them (30\%) having positive pregnancy.

Figure (2): Explain the role of nurses illustrated in satisfaction level. The satisfaction of women who go to the IVF unit at the Woman's Health hospital toward the nurses, the doctors who are treating them and evaluates the unit as a whole, where the result showed that most of the women with suitable level of satisfaction (53\% excellent \& $41 \%$ very good respectively).
Figure (3): Represents that nearly all infertile women undergoing IVF process suffered from a degree of anxiety (Mild 47\%, Moderate 32\% \& severe 21\%) and also the women reach to different level of depression (Mild 58\%, Moderate 28\% \& severe $12 \%)$.

Table (4): Illustrate relationship between outcomes of IVF and personal data, statistical significant differences were found between women Pregnancy outcomes and women age p_value 0.001. As regards occupation and educational level there is no statistical significant differences were found between them and Pregnancy outcomes.

Table (5): There were statistically significance difference (p_value 0.001) regarding the maternal physical health problem and IVF outcomes. The majority of positive pregnancy $(70 \%)$ occurs among women without any health problems while negative pregnancy and fertilization not occur in women complain of health problems as (12 women) with poor ovarian reserve ( 8 women) suffer from tubal, pelvic adhesion, PID, hydrosalpinx, fibroid and endometriosis, (5 women) with PCOs and (4 women) complain of uterine and tubal infection.

Table (6): Reveals that women with increase the period of infertility decrease the probability of positive pregnancy and most of positive outcomes occur in women with primary infertility. As regarding cause of infertility, the results showed that positive pregnancy outcomes decrease when both couple has infertility problems.

Table (7): Represents relationship between outcomes of IVF and psychological factors, statistical significant differences was found between women have pregnancy occur as regard anxiety level and depression level (P_value 0.000).

\section{Discussion}

In-vitro fertilization (IVF) nowadays considers the important and recommended management preference for unresolved infertility (NCCWCH NICE, 2013). Children who have born through IVF worldwide were more than five million. IVF can be stressful physically and emotionally and many predicting 
factors can affecting chances of pregnancy after an ART cycle which can help to prevent overtreatment and to equilibrium the expectation of attain pregnancy after IVF versus the probability of attain pregnancy through natural conception (Van Loendersloot et al., 2010 \& Van Loendersloot et al., 2014). So the aim of current study is to determine physical and psychological factors affecting outcomes among women performed IVF.

The finding of the actual study revealed that the mean age of studied women was $30.1 \pm 4.6$, the majority of women were housewives and more than one third of them had a basic education which in harmony with the study findings of Guliz \& Yilda, (2015) who performed his study to identify relation between anxiety and healthy lifestyle on IVF outcomes, the mean age of women were $31.4 \pm 4.7$, about half of them have primary level of education and near to two thirds were housewives. The present study revealed that about half of women had duration of infertility ranged from 5-10 years and around one third of infertility related to male causes. This was in conformity with Guliz\& Yilda, (2015) who reported that nearly one third of participant women infertile due to male causes and had duration of 6-10 years of infertility.

Concerning physical factors affecting IVF treatments outcomes the current study pointed that the age is the first physical predictor factors affect outcomes whereas the success rate of pregnancy decrease with progress in maternal age with significant relation between them $\mathrm{P}_{\text {_value }} 0.001$, this finding on the same line with shilan, (2016) who applied his study on 125 women in Dwarozh IVF private center in Sulaimanito to know the effect of maternal age on IVF end results and concluded that female age is an essential predictor factor may affect woman's failure to have a live birth after IVF as well as the risk of bad performance at each stage of treatment. Also in the same line with many of studies proved that the increasing of maternal age worse the IVF outcomes through poor ovarian response during it, low retrieved oocyte number, low oocyte fertilization rate, low good quality embryo rate and low pregnancy rate YAN Jun, et al., (2012), so states that women in 20 to 30 years of age will have the best IVF outcomes of the women of fertile age and decrease infertility sets after 30 years age Van Loendersloot, et al., (2014), Siam (2014), Bhattacharya, et al., (2013), Sunkara (2011) \& Gnoth, et al., (2011).

Obesity is also considered to be a factor that affects the success of IVF treatment which affect the reproductive tissues and organs and also affect dosage of gonadotropins. This show that the positive outcomes of pregnancy decrease in women with underweight and obese more than women with ideal weight but it not significant due to few number of sample according to sample size and also because this center has been work since short period (2 years ago), so obese women in large sample may be clarify a significant of this factor, which agree with Moragianni et al., (2012) who done his study at large university-affiliated infertility practice, Massachusetts illustrate that patients with a BMI more than $30 \mathrm{~kg} / \mathrm{m} 2$ have more than two third of sample less chance to have a live birth following their first ART cycle compared with women with a BMI less than $30 \mathrm{~kg} / \mathrm{m}^{2}$.

Also in the same context with a retrospective analysis was performed on Eight hundred ninety-three women at an academic infertility practice, Boston by Shah, et al., (2010) who discuss the effect of BMI on IVF outcomes, revealed that the women with class II and III obesity had much lower peak of estradiol levels, fewer oocytes retrieved and greater incidence of immature oocytes and lower live birth rates compared to subjects with normal BMI (18.5-24.9) and with Merhi, et al., (2013) in retrospective study including three hundred forty-four infertile couples undergoing in-vitro fertilization (IVF) or intracytoplasmic sperm injection (ICSI) cycles was performed at University of Colorado, Denver, USA who found that around half of participating women have normal BMI category was accompanied with increased pregnancy rate than that overweight and obese BMI groups. Many researches support the theory that low and high BMI is accompanied with decreased pregnancy rates. Also, there is a clear bias in the literature because obesity are associated with lower implantation, relation obesity to develop PCOs and are at increased risk for cycle cancellation Davies, et al., (2013), Kayatas, et al., (2013), Singh, et al., (2013) \& Khaskheli, et al., (2013).

Regarding duration of infertility, the existing study mention that the pregnancy decreases as the period of infertility increases, but in this study didn't shown significant relation in duration and no difference between primary versus secondary infertility because number of women with infertility duration more than ten years and secondary infertile women is few number, in my opinion this is because low economic status of women attending to IVF Government center and high cost of this process and ovulation induction drugs so difficult to tray again in short time, this result in concurrent with Nelson \& Lawlor (2011) and van Loendersloot, et al., (2013) whose found that pregnancy rates were slightly lower in couples with a longer duration of subfertility even after adjustment for age and in the same line with Islam, (2016) investigate outcomes on the same number of studied women, conducted in Alkasr Alainy hospital and the Egyptian IVF center, Cairo, Egypt, who 
found that there a significant between longer duration of infertility and IVF outcomes and versus Van Loendersloot, (2010) who didn't find an obvious association between duration of subfertility (in primary versus secondary subfertility) with IVF outcomes.

Concerning to types of infertility the actual study indicate significance relation between female factors which clarify in maternal disease and pregnancy outcomes whereas women with tubal and uterine problems with negative pregnancy outcomes more than women without any diseases. The study state that the majority of positive pregnancy outcomes occur in women free from any disease in Aligned with Lintsen, 2007 cited in Van Loendersloot et al., (2014) who show that there is evidence for a connection between tubal pathology and pregnancy with IVF. Women with tubal pathology alone had a low pregnancy rate compared to women with unexplained subfertility or other indications and also incompatible with Sowter, et al., (2010) who show that the tubal infertility associated with hydrosalpinx affects the opportunity of implantation of a transferred embryo due to the effect of secretions in the fallopian tube which potentially may flow into the endometrial cavity and impair the quality of the decidua.

On the opposite side, another study reported that women with tubal pathology had higher pregnancy chances after IVF compared with couples with unexplained subfertility Van Loendersloot et al., (2014) Likewise other female factors as endometriosis, tubal block, and tubal and uterine adhesion endometritis, fibtomyoma affect positive outcomes of pregnancy articulate in present study and in accordance with Yalanadu \& Nitish, (2014), Bhattacharya, et al., (2013), Tulandi \& Akkour, (2012), YAN Jun, et al., (2012) \& Sunkara, et al., (2010).

Poor ovarian response consider from the important female factors affect outcomes of ART technology, the women defined as "poor responders," mean the limited number of obtained ovum. So as a result of low number of oocytes regain fewer embryos and subsequently lower pregnancy rates although the concept of poor ovarian response was introduced over 30 years ago (Polyzos \& Devroey, 2011). Poor ovarian response is caused by many factors as ovarian surgery in cases of PCOs and others ovarian problems, unexplained infertility, advanced age, and diabetes mellitus type I and other Raffi, et al, (2012), Fritz \& Speroff, (2011) \& de Ziegler, et al., (2010). Also the current study report significant outcomes in thirteen women diagnosed as poor ovarian response failed pregnancy and seven of them the fertilization of ovum not occur and no embryo transfer happen, and seven women with PCOs and diabetes with negative outcomes whereas a result of these finding concordant with Filippo Ubaldi, et al., (2014), De Carvalho, et al., (2012) \& Islam, et al., (2016) whose elucidate the proportion of women with few oocytes was strongly influenced by age, increasing duration of infertility, no previous pregnancy and women with a diagnosis of endometriosis, or anovulation relative to women with an unexplained diagnosis.

The current study declared that mild level of anxiety and depression which related to infertile women ended to ways of IVF management don not affect its outcomes, while the women who exceed the rate of natural anxiety and depression, result in extreme curve have negative outcomes of pregnancy which in accordance with Feijing Zhou, (2016). Who work on 435 infertile women undergoing in-vitro fertilization and embryo transplantation (IVF-ET) shared in the study, conducted in the reproductive medicine center of a university hospital in Henan, Zhengzhou, China to explore whether psychological stress is related to treatment outcome in women undergoing in-vitro fertilization and clarify that higher perceived psychological stress in women undergoing their first cycle of IVF, was related to a rise of FSH and $\mathrm{LH}$ and dosage of GnRha, while a decrease of retrieved oocyte counts, lower high quality embryo rate and clinical pregnancy failure of IVF treatment.

Another studies in the same manner with the existing study showed that psychological stress was negatively associated with a positive pregnancy outcome after IVF Costantini-Ferrando, (2016), Gourounti, et al., (2011) \& Li, et al., (2011). Conversely, other studies declared that psychological stress examinations could not predict pregnancy outcome in ART. However, these studies had a focus on psychological stress measurement with four independent examinations including salivary secretory markers, which was different from the present study focusing on perceived infertility-related stress or differ psychological stress between countries, Egyptian women more stressful than women in European countries and poor economic conditions make the couple more anxious and fear of failure Taguchi, et al., (2015) \& Pasch, et al., (2012).

In same context with Gourounti, et al., (2011) they established in study to assess the relation of infertility-related stress, anxiety, and depressive symptoms and outcomes in women undergoing IVF by utilize hierarchical, sequent logistic regression and controlling for the biomedical factors as a relevant effects outcomes, that after the embryo transfer, above than one third of studying women had a positive pregnancy outcome. After controlling for 
biomedical affecting factors as age, number of oocytes retrieved, and embryos transferred the Logistic analyses evidence that, infertility-specific stress was $(\mathrm{OR}=0.964, \mathrm{P}=.011)$ and nonspecific anxiety was $(\mathrm{OR}=0.889, \mathrm{P}=.006)$ were refer to that the psychological stress was negatively related to invitro fertilization outcome.

On the other hand Hayley, et al., (2013) who demonstrated that psychological symptoms included dysphoria and pessimism were observed within couple undergoing IVF correspond to long period of controlled ovarian hyper stimulation and also lower fertilization rate associated to partner with higher psychological distress. On adjusted analyses, partner's depression score was an independent factor predicts to reduce likelihood of clinical pregnancy.

Despite evidence that nursing counselling is beneficial for those undergoing ART treatments. Nurses who work in fertility clinic often have a primary contact with infertile women and are uniquely existed to assist them with the emotional and psychological effects and stress of IVF. The actual study illustrated that most of women satisfy about services and counseling offer by all health team members in IVF unit at the Woman's Health hospital as a part of psychological effect which help them to reduce depression symptoms illustrated in anxiety and depression tables (only 12 cases with severe depression and 28 cases with anxiety) and based on the opinion of many studied women with previous IVF trails whose dropout from another IVF centers in Assiut during or after treatment due to lack of counseling and poor satisfaction, this finding in agreement with many researches insure the importance of counselling which range from enhanced quality of life, to a decrease in depressive symptoms and improvements in pregnancy rates (Kelly Gray, et al., 2015, Allan, 2013, Wilson \& Leese, 2013 \& Domar \& Prince, 2011) So trained nursing counselors is important part in IVF centers which nurses can assist women undergo ART treatment and can elevate women's stressor.

\section{Conclusion}

Female age, body weight and female factors infertility are the main significant physical factors and also psychological factors as anxiety and depression play a key predictor of low success outcomes in women undergoing IVF. Nursing counselling is important role especially in IVF centers which increase women satisfaction and try to reduce anxiety and depression and makes couples continue IVF management even after failure and return to another trial.

\section{Recommendations}

- Educating women at the beginning, in infertility centers on the impact of physical factors that can affect management is effective part of nurses and physicians active role.

- Improve women's lifestyle as reduce body weight, and seek treatment at young age.

- Offers a peer support group (session for women supporting women) as psychotherapy by trained nurses.

- Trained counselors nurses in Egyptian fertility centers are an important and effective role help to reduce the psychological stressor.

- Larger studies are still required to detect the impact of psychological stressor factors on pregnancy outcome.

\section{References}

1. Adam J., Massey, Bruce Campbell, Nick Raine-Fenning, Navneet Aujla and Kavita Vedhara (2014): The association of physiological cortisol and IVF treatment outcomes, A Systematic Review. Reproductive Medicine and Biology, 13:161-176.

2. Allan H., (2013): The anxiety of infertility: The role of the nurses in the fertility clinic. Human Fertility Journal, Volume 16(1): p. 17-21.

3. Brittany Hamstra, (2017): Fertility And Reproductive Nursing: Helping Family Dreams Come True, https://nurse.org/articles/fertilitynurse-career-guide.

4. Bhattacharya S., Maheshwari A., Mollison J., (2013): Factors Associated with Failed Treatment, an Analysis of 121,744 Women Embarking on Their First IVF Cycles, PLOS one 8(12): 82249. doi:10.1371/journal.pone.0082249, University of Louisville, United States of America, Volume 8 Issue 12 e82249.

5. Costantini-Ferrando M., Joseph-Sohan M., Grill E., Rauch E., \& Spandorfer S., (2016): Does stress affect in vitro fertilization (IVF) outcome? Reproductive Medicine Associates of New Jersey, Cornell Medical College, New York, NY.

6. Coelho, Scott R., Elkind-Hirsch K., StyneGross A., Miller K., Frattarelli J., (2011): The predictive value for in vitro fertility delivery rates is greatly impacted by the method used to select the threshold between normal and elevated basal follicle stimulating hormone. Fertile Sterile; 89: 868-878.

7. Davies D., Caswell W., Reed J., O'Leary R., Hill J., \& Tucker M., (2013): Are the adverse effects of weight on reproductive potential an embryo or endometrial factor? Fertile Sterile, 100 
(Suppl.):S85-S86, Fertility Centers of New England, Volume 100, Issue 3, Supplement, and Pages S85-S86.

8. Domar A., Conboy L., Denardo-Roney J., \& Rooney K., (2013):. Lifestyle behaviors in women undergoing in vitro fertilization: a prospective study. Fertile Steril; 97:697-701.

9. De Carvalho B., Sobrinho D., Damasceno Vieira A., (2012): Ovarian reserve assessment for infertility investigation. ISRN, Obstet. Gynecol. 2:576385. http://dx.doi.org/10.5402/ 2012/576385.

10. Domar, A., \& Prince L., (2011): Impact of psychological interventions on IVF outcome. Sexuality, Reproduction and Menopause Journal, 9(4): p. 26-32.

11. De Ziegler D., Borghese B., \& Chapron C., (2010): Endometriosis and infertility, pathophysiology and management, University Paris Descartes, Centre Hospitalize Universities Cochin, Service of Gynecology\& Obstetric, 76(9742):730-8. Doi: 10.1016/S01406736(10)60490- Vol. 376, no. 9742, pp. 730-738.

12. Eric Levens, (2011): The Important Role of the Infertility https://www.fertilityauthority.com/blogger/drlevens/2011/05/16/important-role- infertilitynurse.

13. El- mistkawy A., (2004): Reliability and validity of Hamilton Rating scale for Depression.

14. Feijing Zhou \& Yuezhi Dong, (2016): Psychological stress is related to treatment outcome in women undergoing in-vitro fertilization and Embryo transplantation, Int $\mathrm{J}$ Clin Exp Med, ;9(4):7481-7488, Reproductive Medicine Center, The First Affiliated Hospital of Zhengzhou University, Zhengzhou, China.

15. Filippo U., Alberto V., Rosario D., \& Laura R., (2014): Management of Poor Responders in IVF: Is There Anything New? Bio-Med Research International, Volume 2014, 352098, 10 pages, http://dx.doi.org/10.1155/2014/352098.

16. Fritz M., \& Speroff L., (2011): Clinical Gynecologic Endocrinology and Infertility, Wolters Kluwer Health/Lippincott Williams \& Wilkins, Philadelphia, Pa, USA, Eighth Edition, ISBN-13: 978-0781779685.

17. Guliz Onat, \& Yilda Arzu, (2015): The effects of a healthy lifestyle and of anxiety levels on IVF outcomes, African Journal of Reproductive Health December: Vol 19, No 4, 101.

18. Gnoth C., Maxrath B., Skonieczny T., Friol K., Godehardt \& Tigges J., (2011): Final ART success rates: a 10 years survey, Hum Reprod, Volume 26, Issue 8, Pages 2239-2246. https://doi.org/10.1093/humrep/der178, 26.
19. Gourounti K., Anagnostopoulos F., Vaslamatzis G., (2011): The relation of psychological stress to pregnancy outcome among women undergoing in-vitro fertilization and intracytoplasmic sperm injection. Women Health; Jun 21; 51(4):321-39.

20. Holden J., (2015): Depression and Anxiety in the Workplace

https://www.mentalhealthcommission.ca/sites/def ault/files/2015-04-29.

21. Hayley S., Quant, Athena Zapantis, Michael Nihsen, Kris Bevilacqua, Sangita Jindal \& Lubna P., (2013): Reproductive implications of psychological distress for couples undergoing IVF, J Assist Reprod Genet. Nov; 30(11): 14511458.

22. Hamilton M., Maier W., Buller R., Philipp M., \& Heuser I., (1988): The Hamilton Anxiety Scale: reliability, validity and sensitivity to change in anxiety and depressive disorders. J Affect Disord; 14(1):61-8.

23. Hamilton M., (1979): A rating scale for depression, J Neurol Neurosurg Psychiatry, 23:56-62.

24. Islam Y., Aboulghar M., AlEbrashy A., \& Omar A., (2016): The value of different ovarian reserve tests in the prediction of ovarian response in patients with unexplained infertility, Middle East Fertility Society Journal, www.mefsjournal.org, www.sciencedirect.com, Volume 21, Issue 2, Pages 69-74.

25. Ibanez, Rockliff H., Lightman S., Rhidian E., Buchanan H., Gordon U., \& Vedhara K., (2012): A systematic review of psychosocial factors associated with emotional adjustment in in vitro fertilization patients. Human Reproduction Update, DOI: 10.1093/humupd/dmu010.

26. Kelly Gray, Janice Copeland, Paula Anderson, \& Jason Hitkari, (2015): Patient utilization of psychological counselling during IVF: implications for nursing practice, Olive Fertility Centre, Vancouver, Canada 2. University of British Columbia, Vancouver, Canada.

27. Kayatas S., Boza A., \& Api M., (2013): Does body composition can be used as a predictive factor of cycle fecundity in unexplained infertile women? Fertil Sterile, 100 (Suppl.):S335.One of the first explanations of the causative relationship between obesity and treatment failure.

28. Khaskheli M., Baloch S., \& Baloch A., (2013): Infertility and weight reduction: influence and outcome, Department of Obstetrics and Gynecology-Radiology, Liaquat University of Medical and Health Sciences, Jamshoro, Journal of the College of Physicians and Surgeons Pakistan, Vol. 23 (11). 
29. Li Y., Yang D., \& Zhang Q., (2015): Impact of overweight and underweight on IVF treatment in Chinese women. Gynecology Endocrinal; 26:416-422, doi: 10.3109/09513591003632118.

30. Li X., Ma Y., Geng L., Qin L., Hu H., \& Li S., (2011): Baseline psychological stress and ovarian norepinephrine levels negatively affect the outcome of in vitro fertilization, Gynecol Endocrinal J; 27 (3), PP 139-143.

31. Lintsen A., Eijkemans M., Hunault C., Bouwmans C., Hakkaart L., Habbema J., \& Braat D., (2007): Predicting ongoing pregnancy, chances after IVF and ICSI: a national prospective study. Hum Repro'd; 22:2455-62. https://www.ncbi.nlm.nih.gov/pubmed/17636281.

32. Merck Serono (2015): In vitro fertilization (IVF) \& intra-cytoplasmic sperm injection (ICSI), Part of the Pathways to Parenthood booklet series, an assisted reproductive technology in Australia and New Zealand. National perinatal epidemiology and Statistics Unit, the University of new south Wales.

33. Merhi Zaher, Julia Keltz, Athena Zapantis, Joshua Younger, Dara Berger, Harry J., Lieman, Sangita K., Jindal, \& Alex J., Polotsky (2013): "Male Adiposity Impairs Clinical Pregnancy Rate by in Vitro Fertilization Without Affecting Day 3 Embryo Quality." Obesity Silver Spring, Md., 21.8: 1608-1612.

34. Moragianni V., Jones S., \& Ryley D., (2012): The effect of body mass index on the outcomes of first assisted reproductive technology cycles. Fertility and Sterility, Vol. 98, No. 1. American Society for Reproductive Medicine, Published by Elsevier Inc.doi:10.1016/j.fertnstert.004.

35. Nccwch Nice, National Collaborating Centre for Women's \& Children's Health (2013): Commissioned by the National Institute for Health and Clinical Excellence, Fertility assessment and treatment for people with fertility problems, Published by the Royal College of Obstetricians and Gynecologists, 27 Sussex Place, Regent's Park, London, 2nd edition.

36. Nelson S., \& Lawlor D., (2011): Predicting live birth, preterm delivery and low birth weight in infants born from in vitro fertilization: a prospective study of 144,018 treatment cycles, PLoS Med, https://doi.org/10.1371/journal.pmed.1000386.

37. Pasch L., Gregorich S., Katz P., Millstein S., Nachtigall R., Bleil M., \& Adler N., (2012): Psychological distress and in vitro fertilization outcome. Fertil Sterile; 98: 459-464. Department of Psychiatry, University of California, San Francisco.
38. Polyzos N., \& Devroey P., (2011): “A systematic review of randomized trials for the treatment of poor ovarian responders: is there any light at the end of the tunnel?" Fertility and Sterility, vol. 96, no. 5, pp. 1058.e7-1061.e7.

39. Raffi F., Metwally M., \& Amer S., (2012): The impact of excision of ovarian endometrioma on ovarian reserve: a systematic review and metaanalysis," The Journal of Clinical Endocrinology \& Metabolism, vol. 97, no. 9, pp. 3146-3154.

40. SCRC, (2016): Southern California Reproductive Center, What Factors Determine IVF Success Rates? Retrieves 2017, https://blog.scrcivf.com/what-factors-determineivf-success-rates.

41. Shilan H., (2016): The effect of maternal age on the outcomes of in vitro fertilization, Sulaimani region, mustansiriya Medical Journal Volume 15 Issue 1, pISSN 2070 - 1128.

42. Siam S., (2014): Gynecologic laparoscopy and reproductive failure: Review of 4103 infertile Egyptian women, Middle East Fertility Society Journal, Volume 19, Issue 2, Pages 102-106. https://doi.org/10.1016/j.mefs.2013.05.011Get rights and content

43. Singh S., Park J., Meyer W., \& Couchman G., (2013): Impact of recipient BMI on pregnancy and implantation rates following IVF/ICSI cycle with donor oocytes, Volume 100, Issue 3, Page S86, American society of reproductive medicine, Fertile Sterile; 100 (Suppl.):S86. : https://doi.org/10.1016/j.fertnstert.07.1949.

44. Steven E., Gregorich, Patricia K., Katz, Robert D., Nachtigall, Millstei G., Bleil E., \& Adler N., (2012): Psychological distress and in vitro fertilization outcome, Volume 98, Issue 2, August, Pages 459-464, doi:10.1016/j.fertnstert.05.023

45. Sunkara S., Rittenberg V., Raine-Fenning N., Bhattacharya S., \& Zamora J., (2011): Association between the number of eggs and live birth in IVF treatment: an analysis of 400135 treatment cycles. Hum Repro'd 26: 1768-1774. doi:10.1093/humrep/der106. PubMed: 21558332.

46. Shah D., Missmer S., Berry K., Racowsky C., \& Ginsburg E., (2010): "Oocyte and Embryo Quality Obese Patients Undergoing in Vitro Fertilization (IVF)."Fertility and Sterility, 94.4: S51.

47. Sowter M., Johnson N., Van Voorst S, Strandell A., \& Mol B., (2010): Surgical treatment for tubal disease in women due to undergo in vitro fertilization, Cochrane Database System Rev Volumes 1. PubMed: 200915311526646411687014. 
48. Steve. C., (2010): Serenity program, depression and feeling low, The Hamilton depression rating scale; 20, (3), Pp. 33-35.

49. Sunkara S., Khairy M., El-Toukhy T., \& Khalaf Y., (2010): The effect of intramural fibroids without uterine cavity involvement on the outcome of IVF treatment: a systematic review and meta-analysis. Hum Report; 25:418-29.

50. Timothy J., (2017): What is depression and what can I do about it? http://www.who.int/mental_health/management/d epression/en.

51. Taguchi S., Hayashi T., Tada Y., Kitaya K., Funabiki M., Iwaki Y., Karita M., \& Nakamura Y., (2015): Do combined psychological stress examinations predict pregnancy outcome in an assisted reproductive technology program? Clin Exp Obstet Gynecol; 42: 309-310 Oak Clinic, Nishinari-ku, Osaka (Japan) CEOG Clinical and Experimental Obstetrics \& Gynecology.

52. Tulandi T., \& Akkour K., (2012): Role of reproductive surgery in the era of assisted reproductive technology. Best Pract Res Clin Obstet Gynaecol; 26(6):747-55.

53. Van Loendersloot L., Repping S., Repping A., Bossuyt P., \& Van der Veen, (2014): Prediction models in in vitro fertilization; where are we? A mini review, Journal of Advanced Research 5, 295-301, Journal of Advanced Research, 20901232, Production and hosting by Elsevier B.V. on behalf of Cairo University, http://dx.doi.org/10.1016/j.jare.05.002.

54. Van Loendersloot L., Van Wely M., Repping S., Bossuyt P., \& Van der Veen., (2013): Individualized decision-making in IVF: calculating the chances of pregnancy. Hum Reprod; University of Amsterdam, ISBN: 978-946191-933-5.

55. Van Loendersloot L., Van Wely M., Limpens J., Bossuyt P., \& Van der Veen, (2010): Predictive factors in in vitro fertilization (IVF): a systematic review and meta-analysis, Human Reproduction Update, Vol.16, No.6 pp. 577-589, Advanced Access publication doi:10.1093/humupd/dmq015.

56. Williams L., \& Wilkins, (2014): The impact of lifestyle behaviors on infertility treatment outcome, Volume 26, Number 3, www.coobgyn.com.

57. Wilson C., \& Leese B., (2013): Do nurses and midwives have a role in promoting the well-being of patients during their fertility journey? A review of the literature. Human Fertility, 16(1): P. 2-7.

58. Yalanadu N., \& Nitish N., (2014): Role of surgery to optimize outcome of assisted conception treatments. The Obstetrician \& Gynecologist, Royal College of Obstetricians and Gynaecologists,15:91-8, Zagazig University, Faculty of Medicine, El Sharkia, Egypt, Middle East Fertility Society Journal, www.mefsjournal.org, www.sciencedirect.com, 19, 102-106.

59. Yan Jun Hao, W., KeLiang, Tang Rong, Ding Ling \& Chen Zi-Jiang, (2012): Effect of maternal age on the outcomes of in vitro fertilization and embryo transfer (IVF-ET), science china, Life Sciences, 55 No.8: 694-698. 